\title{
Study the Formation Possibility of some Iron Slag Based Glasses
}

\author{
H. M. Gomaa ${ }^{1}$, A. G. Mostafa ${ }^{2}$, M. M. H. Eshtewi ${ }^{3}$ \\ ${ }^{1}$ Glass Tech. Dept., Higher Institute of Optics Technology, Cairo, Egypt \\ ${ }^{2}$ Physics Dept., Faculty of Science, El-Azhar University, Cairo, Egypt \\ ${ }^{3}$ Phys. Dept., Faculty of Science, Sert University, Sert, Libya \\ Email address: \\ H_goumaa@yahoo.com (H. M. Gomaa)
}

\section{To cite this article:}

H. M. Gomaa, A. G. Mostafa, M. M. H. Eshtewi. Study the Formation Possibility of some Iron Slag Based Glasses. Modern Chemistry. Vol. 5, No. 1, 2017, pp. 7-10. doi: 10.11648/j.mc.20170501.12

Received: September 5, 2016; Accepted: January 25, 2017; Published: February 24, 2017

\begin{abstract}
In an attempt to take advantage of industrial wastes, Iron slag was used to prepare some of glass samples in an attempt to re-use. The following chemical formula has considered in the preparation process. $(25+x) \%$ slag $+(75-x) \%$ $\left(\mathrm{Na}_{2} \mathrm{~B}_{4} \mathrm{O}_{7} \cdot 10 \mathrm{H}_{2} \mathrm{O}\right)$, where $\mathrm{x}$ has varied among different values. The rapid quenching method has used to prepare the glass samples, of thier molten components at $1200^{\circ} \mathrm{C}$. When $\mathrm{x}>45$ had not be obtained any glasses, in the conditions of preparation. Both FTIR and XRD showed that each sample contains $\mathrm{x} \leq 45$ had formed perfect glass state. Density and molar volume showed that the glass structure became more open with increasing concentration of the slag.
\end{abstract}

Keywords: Slag Glasses, Glasses, Amorphous Materials, Inorganic Compounds, Oxides

\section{Introduction}

Slag glass is known as marble glass or malachite glass, is a type of opaque, streaked pressed glass. Production of slag glass originated in late-19th-century England, where glass manufacturers are thought to have added slag from ironsmelting works to molten glass to create a range of effectsfrom tortoiseshell to marbling. Among other uses, slag glass was a popular material for lampshades. One of the first glass foundries to produce slag glass was the Gateshead, England, firm of Sowerby, which patented its recipe for purple malachite glass in 1878. Sold into the U.S. market as "blackberries and cream," this popular formula was followed by other malachite colors, including a lemon-yellow called Giallo, a drab green called Pomona, a blue malachite called Sorbin and Somersby's famous Brown, which is very difficult to find today. Since the process of making slag glass was shrouded in a certain amount of mystery, stories sprang up to try and account for the process behind the effects. Iron waste is of the most dangerous environmental pollutants as the production of one ton of iron from its basic components leaves behind 2.5 tons of iron slag. To rid the environment of those harmful industrial waste should be recycled in different ways, such as in paving roads or manufacturing types of materials (glass, Ceramics) that can be used in different areas. Iron slag recycling processes represent high environmental and economic benefit to communities. This article aims to have an attempt recycling iron slag in the form of glass that has different properties and uses.

\section{Experimental}

A series of glass samples have been prepared using a slag as a by-product of iron manufacturing, the chemical analysis of the used slag was recorded in table 1. The batch composition has been selected to obye the following chemical formula, $(25+\mathrm{x}) \%$ slag. $(75-\mathrm{x}) \%$ $\left(\mathrm{Na}_{2} \mathrm{~B}_{4} \mathrm{O}_{7} \cdot 10 \mathrm{H}_{2} \mathrm{O}\right)$, where $\mathrm{x}=0,15,25,35,45$ and 50. Each batch has been weighted using an electric balance, then grounded and mixed by an agate mortar. And hence, transferred to porcelain crucibles and melted in an electric muffle furnace at $1200^{\circ} \mathrm{C}$ for two hours. To ensure homogeneous mixtures the melts have been stirred inside the oven from time to time. Each samples have been divided into two parts, the first one has been crushed to fit the X-ray and the Infrared measurements. The second part has been used in its solid form to suit the density and the electrical properties 
measurements. X-ray diffraction carried out by Philips X-ray diffractometric, model (P.W.1390) with $\mathrm{CuK}_{\alpha}$ radiation $(\lambda=$ $1.5406 \AA$ ) and a Mn single-crystal monochromatic, at angles between $2 \theta=10^{\circ}$ and $80^{\circ}$ in steps of 0.2 degree with an integration time $0.4 \mathrm{~s}$ per step. IR transmission spectra have been recorded applying $\mathrm{KBr}$ disk method in Fourier Transform Infrared (FTIR) spectrometer, at room temperature. It is clear from table 1 that $\mathrm{SiO}_{2}, \mathrm{CaO}$ and $\mathrm{Al}_{2} \mathrm{O}_{3}$ are the major oxides appeared in slag. The following table 2 shows the chemical structures for the samples that have been prepared through our available potentials. In other word, the above $70 \%$ slag $\{x>45\}$, could not be obtained in the glassy

phase.

Table 1. The chemical analysis of the slag.

\begin{tabular}{llll}
\hline Oxide formula & $\mathbf{S i O}_{2}$ & $\mathbf{C a O}$ & $\mathbf{A l}_{2} \mathbf{O}_{3}$ \\
\hline Percentage $\%$ & 37.3 & 50.2 & 12.1 \\
\hline
\end{tabular}

Table 2. The chemical composition of the prepared glasses.

\begin{tabular}{llllll}
\hline Sample & $\mathbf{1}$ & $\mathbf{2}$ & $\mathbf{3}$ & $\mathbf{4}$ & $\mathbf{5}$ \\
\hline $\mathrm{Slag} \%$ & 25 & 40 & 50 & 60 & 70 \\
$\mathrm{Na}_{2} \mathrm{~B}_{4} \mathrm{O}_{7} \%$ & 70 & 60 & 50 & 40 & 30 \\
\hline
\end{tabular}

Table 3. Observable IR bands for the studied samples.

\begin{tabular}{|c|c|}
\hline Band Position & Attributed \\
\hline Band About $460 \mathrm{~cm}^{-1}$ & $\begin{array}{l}\text { Si-O bond vibration. The intensity of this band showed an increase with the slag content gradually increased. } \\
\text { Like behavior may be due to the effect of amount of } \mathrm{SiO}_{2} \text { in the glass network matrix structure }[4,5]\end{array}$ \\
\hline Band At $700 \mathrm{~cm}^{-1}$ & B-O-B bending bond vibration [5] \\
\hline Band Around $935 \mathrm{~cm}^{-1}$ & Si-O-Si stretching bond vibration [5] \\
\hline Band About $1052 \mathrm{~cm}^{-1}$ & $\mathrm{~B}-\mathrm{O}$ bond vibration belongs to $\mathrm{BO}_{4}$ groups [6] \\
\hline Band around $1240 \mathrm{~cm}^{-1}$ & $\mathrm{~B}-\mathrm{O}$ bond vibration in $\mathrm{BO}_{3}$ groups [7] \\
\hline Bands In between 1380 and $1420 \mathrm{~cm}^{-1}$ & $\mathrm{~B}$ - O symmetric stretching vibration of various borate groups [8] \\
\hline Bands Behind $1500 \mathrm{~cm}^{-1}$ & $\begin{array}{l}\text { Some } \mathrm{OH}, \mathrm{H}-\mathrm{O}-\mathrm{H} \text { groups or may be due to the presence of some hydrogen bonds. Like bands may be due to } \\
\text { the used } \mathrm{KBr} \text { disk technique }[9,10] \text {. }\end{array}$ \\
\hline
\end{tabular}

\section{Results and Discussion}

Each sample has been inspected for check the glass phase formation by the structural point of view and FTIR as well as $\mathrm{XRD}$. XRD is an important tool to check and look up the glassy phase formation. Therefore it been used to inspect the samples and in the look up to their structural forms. Fig. 1 exhibits XRD charts for the studied samples containing $70 \%$ and $25 \%$ of slag, only as an example for all samples. No crystallization peaks have been observed in the charts, at all, but each one showed only a broad hump about $2 \Theta=40^{\circ} \mathrm{C}$. Hence, in addition to the visual examination the XRD patterns it can be state and confirm that every prepared sample has showed a good glass phase formation [1-2-3]. FTIR have been used for determine the structural units/blocks in addition to the bond shapes for the studied glasses.

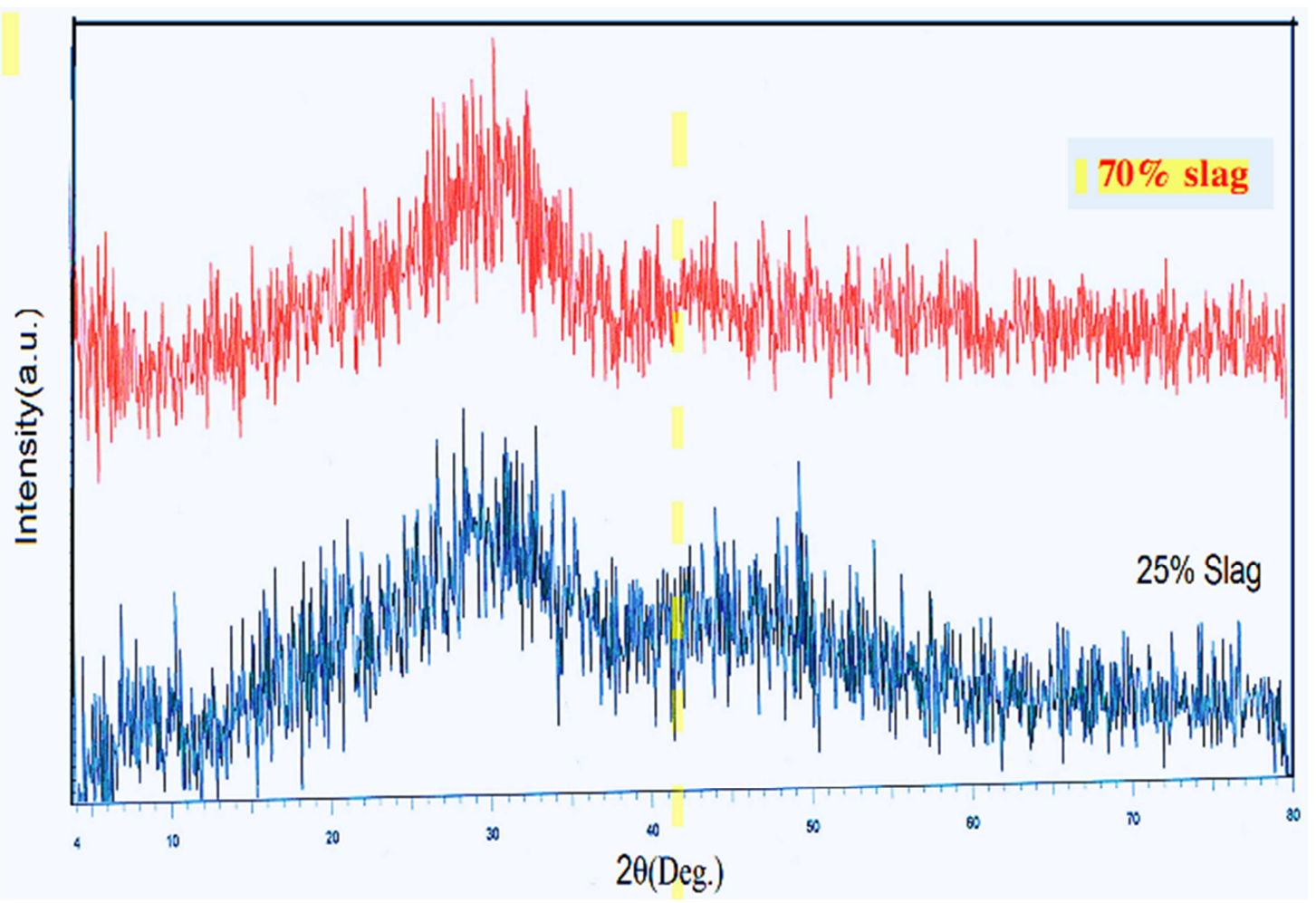

Fig. 1. XRD spectra of $x=25$ and $x=70$ glasses. 
IR charts, for all samples, in the range from $(4000) \mathrm{cm}^{-1}$ to (400) $\mathrm{cm}^{-1}$ at $300 \mathrm{~K}$, have been displayed in Figs. 2, 3, 4, 5 and 6. All charts have been collected in fig. 7 for comparison. After carefully inspecting more than one time, many different bands observed at the FTIR spectra for each sample. By referring and according to the previous literatures these bands can be illustrated, as mentioned in table 3. By study the information in table 3 , it can be concluded that B-O bonds (short bond length) be replaced by that of Si-O (high bond length) with the increasing of slag concentration. Like that behavior may cause the structure of the high slag concentration samples to be more open than that of low slag concentration.

Density measurement is an important sensitive tool to check the fine changes in the hard structures, whereas the molar volume is directly related to the spatial structure of the glass. The liquid displacement method has been used to obtain density of the studied glass samples, in their solid form. Fig. 8 exhibits the measured density, for all samples, as a function of the slag content. As check Fig. 8, it can be observed clearly that the density values showed gradually decrease with the slag content increase. Such behavior may due to the effect of the slag contents $\left\{\mathrm{Si}_{2} \mathrm{O}-\mathrm{CaO}-\mathrm{Al}_{2} \mathrm{O}_{3}\right\}^{+}$ on the glass matrix. Whereas $\mathrm{B}-\mathrm{O}$ replaced by $\mathrm{Si}-\mathrm{O}$ and $\mathrm{Na}^{+}$ by $\mathrm{Ca}^{2+}$ and $\mathrm{Al}^{3+}$. And/or decreasing of the high density compound $\mathrm{Na}_{2} \mathrm{~B}_{4} \mathrm{O}_{7}$.

Since the molar volume is directly related to the internal spatial structure of solid/glass the internal spatial structure, it is more suitable to calculate it to check the changes in the structure of the studied glasses/solids [11]. In addition to the density, Fig. 8 exhibits the calculated molar volume for the all studied glasses. It is clear that the molar volume has behavior against that of density, where it is appeared to increase with the slag content gradually increase. Which means that some defects and/or deformations takes place in the studied glasses as the slag content increased. Like behavior refer that the sample's structure became more open with increase the slag concentration, in an agreement with FTIR data.

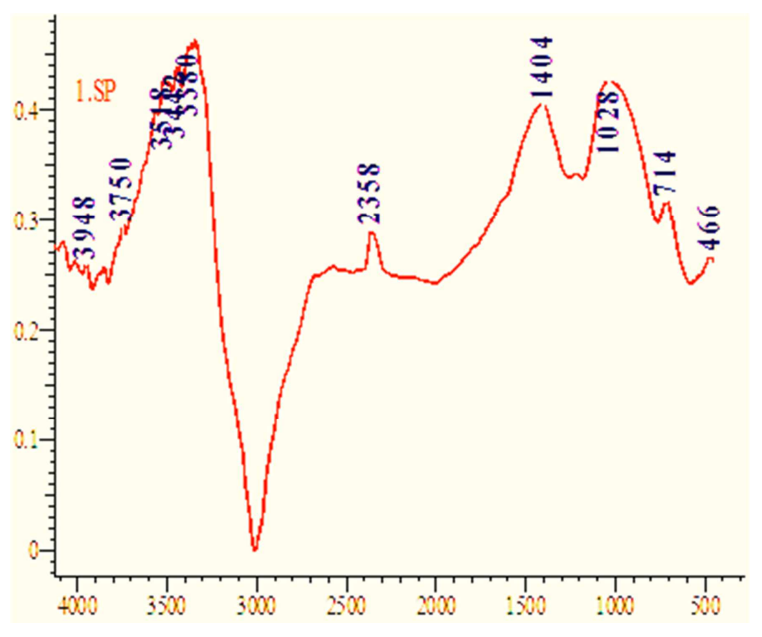

Fig. 2. IR spectra of $x=0$.

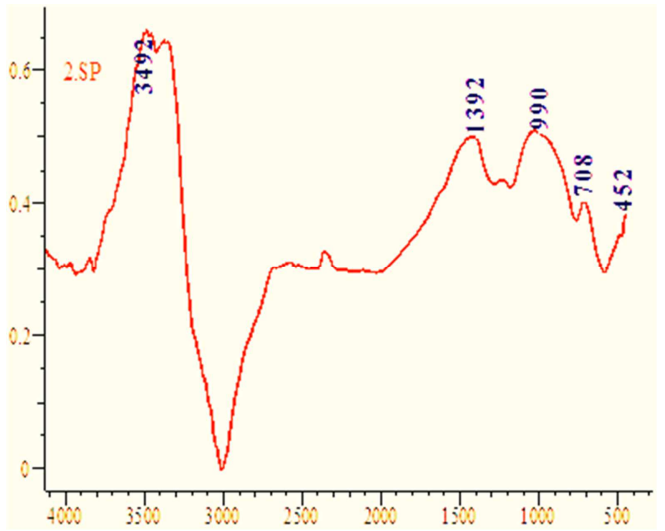

Fig. 3. IR spectra of $x=15$.

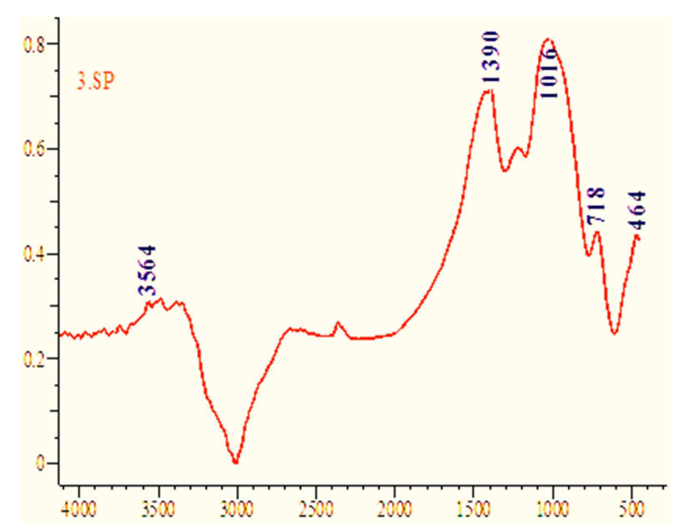

Fig. 4. IR spectra of $x=25$.

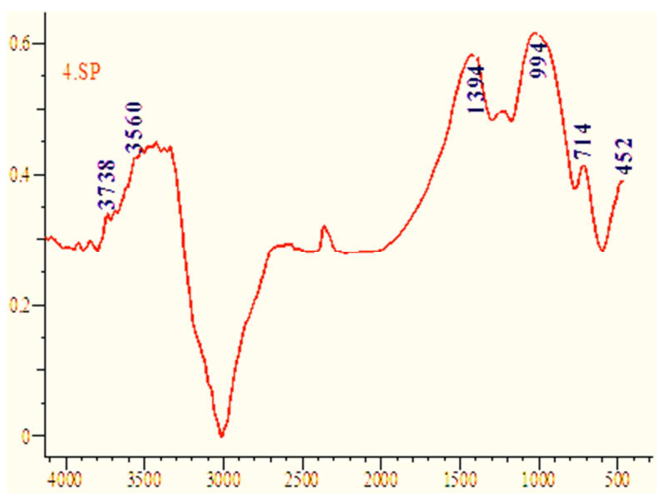

Fig. 5. IR spectra of $x=35$.

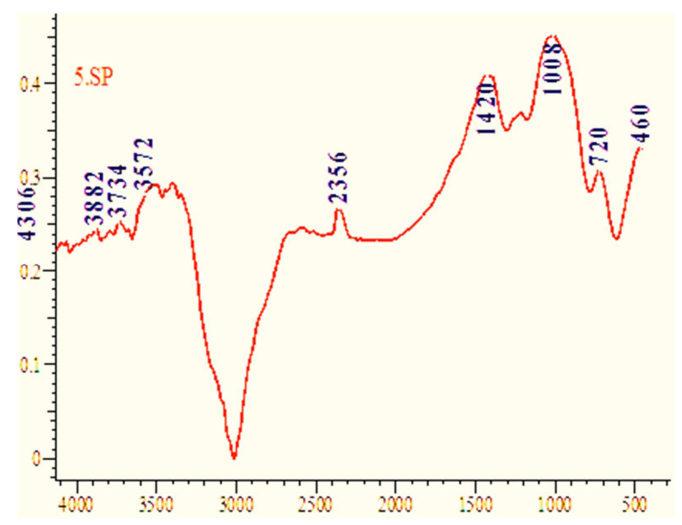

Fig. 6. IR spectra of $x=45$. 


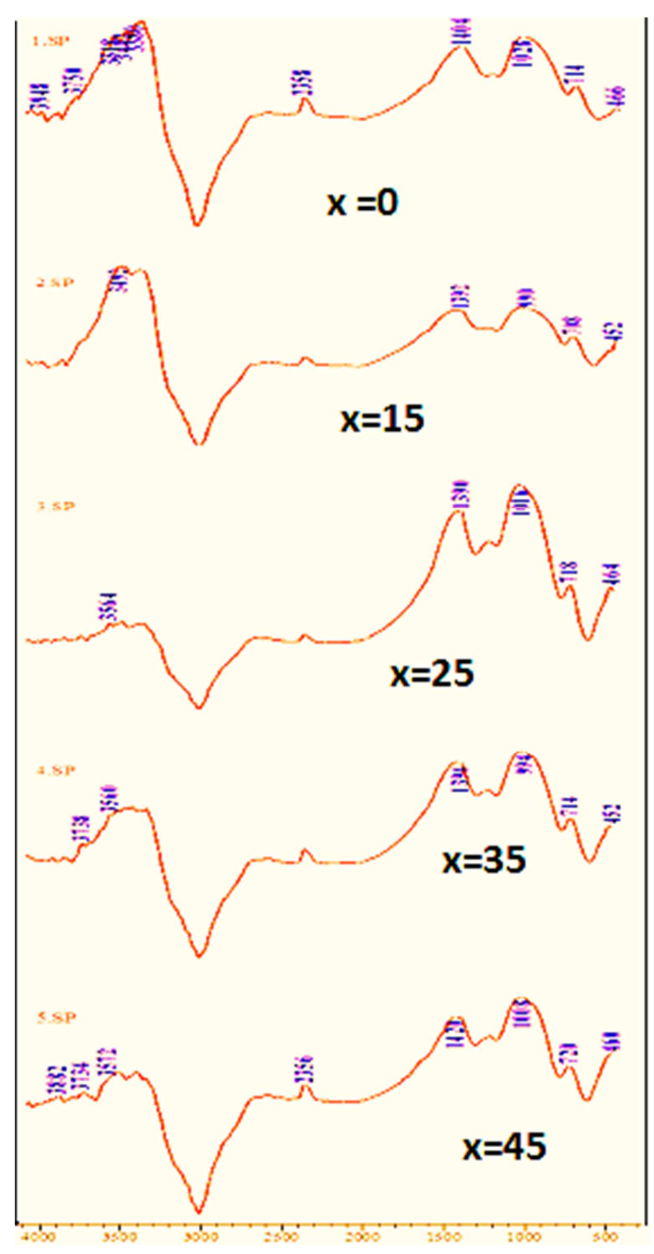

Fig. 7. All IR charts for comparison.

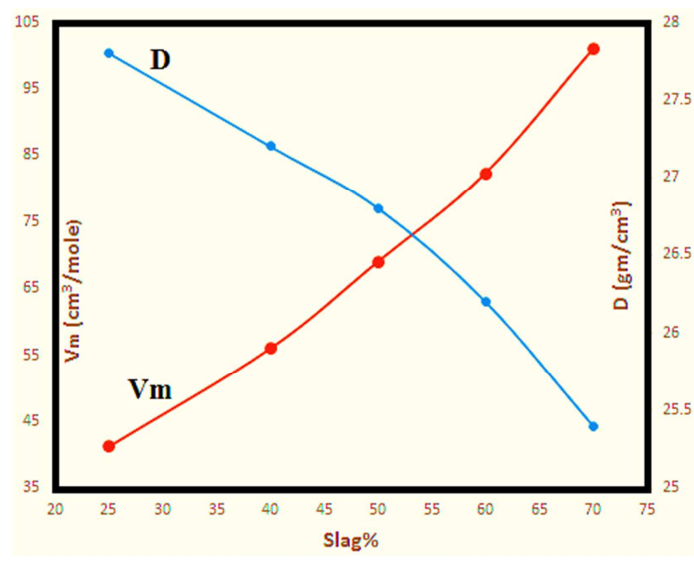

Fig. 8. The Density and molar volume of all samples.

\section{Conclusion}

A set of some oxide glass samples have been prepared using an iron slag, by the quenching mellt method, based on the chemical formula $(25+\mathrm{x}) \%$ slag $+(75-\mathrm{x}) \%$ $\left(\mathrm{Na}_{2} \mathrm{~B}_{4} \mathrm{O}_{7} \cdot 10 \mathrm{H}_{2} \mathrm{O}\right)$, where $\mathrm{x}=0,15,25,35,45$ and 50 , all samples $\{\mathrm{x} \leq 45\}$ are of good glassy states. Both of the density and the molar volume showed that a compactness behavior in the studied glass samples as the slag content increased. The electrical conductivity exhibited a decrease with the slag content increase. The Increase in the proportion of slag caused a increase in the molar volume of the samples and decrease in their densities. also it can be expected that the replacement of $\mathrm{Na}^{+}$by $\mathrm{Ca}^{2+}$ and $\mathrm{Al}^{3+}$ may cause an increase in the electrical conductivity with increase the slag concentration. This mean that like those materials may contain ionic and/or electronic conductivities, therefore they could use in several areas, such as dry batteries and the switching keys.

\section{References}

[1] A. Paul, "Chemistry of Glasses", Chapman and Hall (1982).

[2] J. Swenson and L. Börjesson, J. Non-Crystalline Solids, 232, 658 (1998).

[3] S. Kumar, Ph. Vinatier A. Levasseur, and K. J. Rao, J. Solid state Chemistry, 177, 4-5, (2004).

[4] R. J. Barczynski and L. Murawski J. Non-Crystalline Solids 307-310, 1055-1059 (2002).

[5] I. Kashif, H. Farouk, A. M. Sanad and S. A. Aly, J. Material Science, 27, 122-126 (1992).

[6] E. I Kamitsos and M. A. Karakassides, J. Phys. Chem. Glasses, 30, 229 (1989).

[7] C. R. Kurkjian. J. Non. Cryst. Solids 3, 157 (1970).

[8] J. M. D. Coey, J. Phys. 35 C6-89 (1974).

[9] Schoze, H, Glass ind., 47, 11, 622 (1966).

[10] Husung, R. D and R. Doremus, M., J. Mat. Sci., 5, 10 (1990).

[11] N. J. Kreidl, Glass Science and Technology, Volume 4B chapter 5, ME in glass-other G. Tomandl- (A cademic Press, Inc. (1990). 